\title{
The Crosstalk between Hypoxia and Innate Immunity in the Development of Obesity-Related Nonalcoholic Fatty Liver Disease
}

\author{
María Teresa Arias-Loste, ${ }^{1,2}$ Emilio Fábrega,,2 Marcos López-Hoyos, ${ }^{3,4}$ and Javier Crespo ${ }^{1,2}$ \\ ${ }^{1}$ Gastroenterology and Hepatology Department, Marqués de Valdecilla University Hospital, 39008 Santander, Spain \\ ${ }^{2}$ Infection, Immunity and Digestive Pathology Group, Research Institute Marqués de Valdecilla (IDIVAL), 39008 Santander, Spain \\ ${ }^{3}$ Transplant and Autoimmunity Group, Research Institute Marqués de Valdecilla (IDIVAL), 39008 Santander, Spain \\ ${ }^{4}$ Immunology Department, Marqués de Valdecilla University Hospital, 39008 Santander, Spain
}

Correspondence should be addressed to María Teresa Arias-Loste; ariasloste@gmail.com

Received 24 April 2015; Revised 26 August 2015; Accepted 30 August 2015

Academic Editor: Luca Miele

Copyright (C) 2015 María Teresa Arias-Loste et al. This is an open access article distributed under the Creative Commons Attribution License, which permits unrestricted use, distribution, and reproduction in any medium, provided the original work is properly cited.

\begin{abstract}
Nonalcoholic fatty liver disease (NAFLD) has become a major health issue in western countries in parallel with the dramatic increase in the prevalence of obesity and all obesity related conditions, including respiratory diseases as obstructive sleep apneahypopnea syndrome (OSAHS). Interestingly, the severity of the liver damage in obesity-related NAFLD has been associated with the concomitant presence of OSAHS. In the presence of obesity, the proinflammatory state in these patients together with intermittent episodes of hypoxia, characteristic of OSAHS pathogenesis, may lead to an enhanced inflammatory response mediated by a positive feedback loop mechanism that implicates HIF-1 and NF $\kappa B$. Thus, the severity of liver involvement in obese NAFLD patients with a concomitant diagnosis of OSAHS could be explained. In this review, we focus on the molecular mechanisms underlying the hepatic response to chronic intermittent hypoxia and its interaction with innate immunity in obesity-related NAFLD.
\end{abstract}

\section{Introduction}

Nonalcoholic fatty liver disease (NAFLD) encompasses a wide spectrum of liver damage ranging from simple steatosis to different grades of lobular inflammation, hepatocellular ballooning, and fibrosis (nonalcoholic steatohepatitis; $\mathrm{NASH}$ ) that may eventually lead to an end stage liver disease $[1,2]$. Over the past decade, NAFLD has become a growing medical problem and the main cause of liver disease in industrialized countries $[3,4]$. This increase in the prevalence of NAFLD mirrors the emerging epidemic of obesity and metabolic syndrome in this setting $[5,6]$, which turns into a rise in all obesity-related comorbidities [7], with special interest in different respiratory conditions including the obstructive sleep apnea-hypopnea syndrome (OSAHS) [8]. According to different prevalence studies, in up to $90 \%$ of cases of obesity, understood as a body mass index (BMI) higher than $30 \mathrm{~kg} / \mathrm{m}^{2}$, exists a concomitant NAFLD diagnosis $[7,9,10]$.

Recently, the severity of obesity-related NAFLD and more specifically in cases of morbid obesity (BMI higher than $40 \mathrm{~kg} / \mathrm{m}^{2}$ ) has been associated with the concomitant diagnosis of OSAHS [11, 12]. But this association is not obesity specific and has been described in population with a BMI lower than $35 \mathrm{~kg} / \mathrm{m}^{2}$ and in pediatric population, irrespective of the concomitant presence of insulin resistance $[13,14]$. The prevalence of OSAHS is higher in men than women and has a direct correlation with the BMI and the hip-waist index [15]. It is estimated that up to $60 \%$ of patients with a BMI higher than $30 \mathrm{~kg} / \mathrm{m}^{2}$ will develop OSAHS $[16,17]$. One of the pathophysiological hallmarks of OSAHS is the presence of intermittent episodes of sleeping hypoxia due to the apnea-hypopneas [18]. Intermittent hypoxemia is currently considered a potential major factor contributing to the 
pathogenesis of OSAHS-related comorbidities. In the long term, these intermittent episodes of hypoxia involve the development of different cellular adaptive mechanisms, in which hepatocytes are included [19-25]. These mechanisms involve the hypoxia-inducible factor (HIF) transcription factors, which are master regulators of the cellular response to the hypoxia and coordinate a transcriptional program that guarantee an adequate metabolic, vascular, and functional response to oxygen deficiency [26]. Moreover, recently how HIF transcription factors can be key elements also in the control of immune cell metabolism and functionality has been described [27].

Therefore, the aim of this review is to go through the molecular mechanism underlying the hepatic response to chronic intermittent hypoxia and to discuss its interaction with innate immunity in the setting of obesity-related NAFLD.

\section{Cellular Consequences of Hypoxia}

2.1. Hypoxia-Inducible Factor. The cellular adaptation to hypoxia lies on the HIF transcription factor that is made up of the HIF- $1 \beta$ subunit, which is constitutively expressed, and two $\alpha$ subunits: HIF- $1 \alpha$ and HIF- $2 \alpha$ [28]. This transcription factor regulates the expression of multiple genes involved in oxygen transportation, angiogenesis, proliferation, and metabolism, enabling a cell to counteract a hypoxic environment [26].

Under normoxic conditions, the iron-dependent enzymes prolyl hydroxylases (PHDs) present in the cytoplasm are active and hydroxylate HIF- $\alpha$, leading to its proteosomic degradation mediated by von Hippel-Lindau (VHL) dependent ubiquitination. Contrary to this mechanism, when oxygen levels decrease, PHDs are inactive and therefore HIF- $\alpha$ can accumulate, stabilize, and, eventually, translocate to the nucleus. Another level of regulation is constituted by the factor inhibiting HIF (FIH). FIH hydroxylates asparaginyl residues in HIF-1 $\alpha$ and HIF- $2 \alpha$, reaching the blockade of protein interactions between HIF- $\alpha$ and different coactivators like P300 that form the transcriptional complex. Oxygen acts as a cofactor of FIH and therefore when oxygen is scarce, the ability of FIH to hydroxylate HIF residues decreases leading again to HIF- $\alpha$ accumulation, stabilization, and nuclear translocation $[29,30]$.

2.2. HIF and Innate Immunity: Association with TollLike Receptors. Besides this posttranscriptional and oxygendependent HIF regulation, there are other mechanisms of HIF regulation at a transcriptional level that are oxygenindependent and work under inflammatory, infectious, or oxidative stress conditions [31]. In this sense, how bacterial lipopolysaccharide (LPS), a cell membrane component of Gram-negative bacteria, can increase HIF- $1 \alpha$ transcription has been previously shown [32]. Bacterial products are recognized by Toll-like receptors (TLRs) expressed on myeloid cells. The downstream signaling of TLR involves $\mathrm{NF} \kappa \mathrm{B}$, which plays a central role in regulating the immune response to infection and inflammation, and also induces a HIF- $1 \alpha$
mRNA transcriptional response. Moreover, key inflammatory cytokines, as tumor necrosis factor alpha (TNF- $\alpha$ ), can induce HIF-1 $\alpha$ expression in innate immune cells [33]. Under oxygen shortage conditions, the expression and signaling transduction of TLRs increase, resulting in an amplification of the NF $\kappa$ B pathway [34]. Thus, the innate immune response is enhanced and amplified.

\section{The Role of Hypoxia in Obesity-Related Nonalcoholic Fatty Liver Disease}

3.1. Effect of Hypoxia in the Liver. The repercussion of intermittent hypoxia in the liver has been assessed in different animal models addressing its consequences mainly in terms of hepatocyte injury [22,24], lipid accumulation [21], and endothelial dysfunction [20]. First, Savransky et al. demonstrated in animal models that intermittent hypoxia is able to induce mild liver injury, being its main effect to predispose the liver to the hepatocellular damage seen in different settings, as alcohol intake, drug-induced hepatotoxicity, or the low-grade inflammation present in the metabolic syndrome [25].

Regarding NAFLD and NASH, how literature supports a key role of hypoxia in lipid metabolism is of interest [35]. Importantly, Piguet and collaborators showed in mice models of nonalcoholic steatohepatitis how hypoxia upregulates genes involved in lipogenesis, like SREBP-1c (sterol-regulatory-element-binding protein-1c), PPAR-gamma (peroxisome-proliferator-activated receptor-gamma), ACC1 (acetylCoA carboxylase 1), or ACC2 (acetyl-CoA carboxylase 2), whereas genes involved in lipid metabolism as PPARalpha (peroxisome-proliferator-activated receptor-alpha) and CPT-1 (carnitine palmitoyltransferase-1) were downregulated [23]. Moreover, hypoxia has been also associated with upregulation of genes involved in lipid uptake and lipid droplet formation [36,37]. Several works have focused on the role of HIF signal-transduction pathway in lipid metabolism and liver damage under hypoxic conditions. Thus, Rankin et al. showed in different animal models that HIF- $2 \alpha$ acts as a key regulator of hepatic lipid metabolism, as it impairs fatty acid $\beta$-oxidation, increases lipid storage capacity, and decreases lipogenic gene expression, all of these resulting in the development of severe hepatic steatosis [38]. Later, Qu and collaborators working with animal models that overexpressed HIF through VHL-disruption demonstrated that, besides a time-dependent effect of HIF on lipogenic gene expression, a rapid increase in proinflammatory cytokines and fibrogenic gene expression was also observed in hypoxia [39].

Nevertheless, conflicting results have been observed regarding HIF- $1 \alpha$ downstream signaling in the liver. More than a decade ago, Yun et al. [40] elegantly showed in an animal model how hypoxia inhibits adipogenesis via HIF1 through repression of $P P A R \gamma 2$ promoter activation by the HIF-1-regulated gene DEC1/Stra13. More recently, Nishiyama et al. have suggested that HIF- $1 \alpha$ may act as a protective factor against lipid accumulation in ethanol-induced liver damage through activation of DEC1 [41]. These results are in agreement with different studies that have shown beneficial effects 
of short-term intermittent hypoxia in terms of endothelial function, mitochondrial activity, and steatosis development $[42,43]$. In contrast, Nath and collaborators [22] showed that alcohol intake leads to hepatic fat accumulation through HIF$1 \alpha$ activation in mice engineered with hepatocyte-specific HIF- $1 \alpha$ activation, whereas hepatocyte-specific deletion of HIF- $1 \alpha$ conferred protection from alcohol. Moreover, how the coexistence of alcohol and lipopolysaccharide (LPS) mediated liver damage enhanced hepatic steatosis through induction of monocyte chemoattractant protein 1 (MCP1) via HIF- $1 \alpha$ activation was demonstrated.

The effect that hypoxia exerts on insulin signaling is also of great interest, as insulin resistance is a characteristic hallmark in fatty liver development. In this sense, previous studies in liver specific Phd3 (an isoform of prolyl hydroxylases) knockout mice have suggested that stabilization of hepatic HIF- $2 \alpha$ turns out into improved insulin sensitivity [44]. In line with this study, Wei et al. [45] demonstrated a link between HIF- $2 \alpha$ expression, but not HIF- $1 \alpha$ in murine liver, and an increase in hepatic insulin sensitivity through the induction of insulin receptor substrate 2. This study also pointed out the distinct roles in hepatic metabolism for HIF- $1 \alpha$, which promotes glycolysis, versus HIF- $2 \alpha$, which suppresses gluconeogenesis.

Finally, hypoxia is a major feature in many solid tumors, including hepatocellular carcinoma (HCC). It can promote tumor progression in a mechanism at least partially promoted by HIF-1 that activates hypoxia-responsive genes that will interplay in the natural history of HCC. These genes will mediate in multiple aspects of proliferation, metabolism, angiogenesis, invasion, metastasis, or therapy resistance [4648].

3.2. Consequences of Hypoxia in Adipose Tissue. Expanded subcutaneous and visceral fat is a hallmark of obesity. As a result of this, the enlarged adipose tissue produces and releases different proinflammatory cytokines and adipokines that will be, at least in part, responsible for the low-grade proinflammatory state associated with obesity [49-51]. Recently, it has been suggested that fat inflammation can also be triggered by hypoxic conditions [52]. The reduction in oxygen availability in adipose tissue of obese patients, irrespective of concomitant respiratory conditions, responds to different factors. When adipocytes get bigger, the oxygen diffusion can be impaired, oxygen supply may be reduced due to a decrease in capillary density, and finally and as shown in a recent study obesity and high-fat diet can also increase oxygen consumption in adipocytes, probably due to uncoupled respiration induced by free-fatty acids [53-56]. Moreover, oxygen shortage in adipose tissue will lead not only to the production of adipokines and proinflammatory cytokines [57], but also to an impaired glucose homeostasis and lipid metabolism [58, 59]. Furthermore, hypoxia also inhibits adipogenic differentiation, which favors adipocyte enlargement, with the perpetuation of the situation [40]. Taking together all this data, it can be assumed that adipose tissue hypoxia is a major driver of cardiovascular and metabolic entities associated with obesity and mediated by inflammation. According to this, how the deletion of HIF-1 $\alpha$ in adipocytes enhances glucagon-like peptide-1 secretion and reduces adipose tissue inflammation has been shown, improving glucose tolerance. This points out a potential new target in obesity-related comorbidities [60].

\section{Innate Immunity in Nonalcoholic Fatty Liver Disease: Role of Toll-Like Receptors}

The high prevalence of cardiovascular comorbidity in NASH patients is assumed to be associated with a low-grade proinflammatory state [61], initiated mainly in the expanded visceral fat and at least partially perpetuated in the liver $[62,63]$. Activation of inflammatory pathways in both fat tissue and liver includes those dependent on TLRs and merges mainly in the activation of $\mathrm{NF} \kappa \mathrm{B}$ [64-66]. TLRs are pattern recognition receptors that characteristically perceive pathogenic microorganisms and bacterial-derived molecules, leading to the production of different proinflammatory cytokines $[67,68]$. Among the thirteen different TLRs that have been described in mammals, only TLR2, TLR4, TLR5, and TLR9 have been documented to clearly associate with NAFLD pathogenesis and progression [69-74].

The role of TLR4 has been extensively assessed in both animal models and humans. TLR4 forms a complex with MD2 on the cell surface that specifically binds and responds to bacterial LPS [75, 76]. Circulating LPS levels appear increased in animal models and patients with a diagnosis of NAFLD, but also in patients with insulin resistance [7779]. This endotoxemia may be explained by different factors associated with gut microbiota, gut permeability, and highfat diet [80-84]. Furthermore, LPS can also be increased in patients undergoing intestinal bypass or in patients with total parenteral nutrition, resulting in the development of steatosis that can occur irrespective of the presence of other features of the metabolic syndrome [85-87]. The determinant role of this TLR4-LPS interaction and downstream signalling in NAFLD pathogenesis has been documented in TLR4 mutant mice in which, besides the presence of similar plasmatic levels of LPS compared to wild type animals, the expression of proinflammatory cytokines was suppressed and neither NAFLD nor insulin resistance was developed [70, 88].

Additionally, it is important to note that TLR4 can also respond to free-fatty acids (FFA). In this line, a recent study in human monocytes has demonstrated that FFA can activate TLR4 in the presence of high levels of glucose [89]. This phenomenon can be explained due to the fact that lauric acid, a medium chain fatty acid also present in LPS, can exert downstream signaling dependent on TLR4 in macrophages [90, 91]. Thus, saturated fatty acids, whose levels are frequently increased in plasma of obese patients, can play a key role in the development of diet-induced IR, as has been previously reported [92].

Different studies have implicated TLR4 in the pathogenesis of HCC in NAFLD $[93,94]$. In the last decade, a number of studies have addressed the implication of proinflammatory signaling transduction and carcinogenesis [95-97]. In this line, Dapito et al. established in a recent study the importance of the LPS-TLR4 pathway in hepatocarcinogenesis 
in several genetically different mouse lines in which HCC was induced following different protocols. This way, they could demonstrate that inactivating TLR4 had no effect on HCC incidence but significantly reduced tumor size and number. Additionally, in wild type mice intoxicated with $\mathrm{DEN} / \mathrm{CCl}$, they found that continuous administration of LPS increased tumor number and size [93]. Although in this study no association between TLR4 pathway and incidence was observed, previously $\mathrm{Yu}$ et al. did find this association [98]. This discrepancy might be explained by the different source of the LPS used as TLR4-agonist implicated in HCC development.

Regarding other TLRs implicated in NAFLD pathogenesis, TLR2 is also a cell surface receptor, which is involved in the recognition of a wide range of pathogen-associated molecular patterns (PAMPs) including peptidoglycan, a component of the cell surface of Gram-positive bacteria [75]. These subtypes of bacteria include Firmicutes, whose increase has been reported in animal models and humans subjected to a high-fat diet [99]. Furthermore, this dysbiosis has also been associated with NAFLD [100]. The connection between gut microbiota and NAFLD has been previously addressed in different studies. Thus, research on mice on a high-fat diet has shown that the blockade of TLR2 signaling prevents the development of insulin resistance [80]. Moreover, TLR2 deficient mice with a dietary-induced NASH do not develop steatohepatitis and display lower expression of proinflammatory cytokines [101, 102].

Briefly, according to TLR5 and TLR9, whereas TLR5 is another cell membrane receptor, TLR9 is the only intracellular TLR implicated in NAFLD pathogenesis. TLR5 recognizes the flagellin protein component of bacterial flagella and has not been directly associated with NASH but with dysbiosis and related metabolic syndrome [74, 103, 104]. Thus its role in NAFLD pathogenesis remains to be clarified. TLR9 recognizes unmethylated DNA motifs that are frequently present in bacteria and viruses but rare in mammalian cells. Studies in TLR9 (-/-) mouse models of NASH have shown that TLR9 downstream signaling is associated with NASH severity and fibrosis by the production of IL-1 $\beta$ [105]. Finally, in animal models of colitis with high portal levels of LPS, an increase in hepatic TLR9 mRNA levels associated with hepatic steatosis, inflammation, and fibrosis has been documented [106].

\section{Interaction between Hypoxia and Inflammatory Pathways in the Development of Obesity-Related Nonalcoholic Fatty Liver Disease}

Lipid accumulation in the form mainly of triglycerides is the distinctive trait of NAFLD. In less than $25 \%$ of cases, this deposit leads to a variable degree of lobular inflammation and hepatocellular injury and, consequently, a higher risk of disease progression $[1,107]$. The reasons why liver diseases eventually progress to more severe forms only in some patients remain to be fully elucidated and are subject of study and debate. Thus, in 1998 Day and James expound the classic "two-hit" hypothesis of NAFLD pathogenesis [108]. According to this hypothesis, the disease pathogenesis is sequential, with a first hit consisting in an excessive intrahepatic lipid accumulation, which can be followed by a second hit, resulting in inflammation, hepatocellular damage, and, therefore, NASH. A decade later, Tilg and Moschen proposed the so-called "multiple parallel hits" hypothesis [109] where it was suggested that disease pathogenesis may not be sequential. According to this work, inflammation could precede steatosis in certain scenarios and NASH development could be the consequence of different parallel hits derived from the gut and/or the adipose tissue. Interestingly, in this setting, many cytokines, adipokines, and inflammatory signaling networks mainly regulated by innate immunity emerged as key elements in the disease progression.

As previously mentioned, the activation of inflammatory pathways in NAFLD, not only in the liver, but also in the adipose tissue, with eventual reflection in the liver, includes those dependent on TLRs and merges mainly in the activation of $\mathrm{NF} \kappa \mathrm{B}$ [64-66]. Importantly, it has been demonstrated that $\mathrm{NF} \kappa \mathrm{B}$ is a critical transcriptional activator of HIF- $1 \alpha$ and basal $\mathrm{NF} \kappa \mathrm{B}$ activity is required for HIF- $1 \alpha$ protein accumulation under hypoxic conditions [110]. Moreover, hypoxia may modulate innate immune response in the setting of an infection or inflammation by transcriptional regulation of TLRs expression and function via HIF- $1 \alpha[34,111]$. Thus, the inflammatory scenario present in NASH may boost and possibly perpetuates the consequences of hypoxia in both the liver and adipose tissue. This overexpression of HIF$1 \alpha$ under inflammatory conditions can possibly explain the divergences seen in previously mentioned studies assessing its role in NAFLD, since the consequences of hypoxia may differ in the setting of simple steatosis compared to NASH $[22,41]$. Furthermore, proinflammatory cytokines as IL-6, IL1 , and TNF- $\alpha$ will also contribute to the "vicious circle" of steatosis and inflammation by increasing the lipid deposits through a mechanism that implicates TLRs and leads to insulin resistance $[49,105,112,113]$.

Summarizing, as previously suggested by Savransky et al. [25], chronic intermittent hypoxia can be considered to predispose to liver injury sensitizing the liver to a second insult. In the presence of obesity, the proinflammatory state in these patients together with intermittent episodes of hypoxia may lead to an enhanced inflammatory response mediated by a positive feedback loop mechanism that implicates HIF-1 and $\mathrm{NF} \kappa \mathrm{B}$, which could explain the presence of more severe forms of liver involvement in obesity-related NAFLD in the presence of OSAHS [11]. Thus, hypoxia could be considered as another "hit" among the "multiple parallel hits" that have been suggested as responsible for disease pathogenesis.

\section{Concluding Remarks}

Obesity and obesity-related comorbidities, including respiratory conditions as OSAHS, are dramatically increasing in the last decades. In this scenario, different pathogenic mechanisms coexist with a complex molecular signaling network in which inflammation plays a preeminent role. In line with this, it is important to better define and understand the interaction 
of different etiologies in the same individual that eventually may lead to insulin resistance, metabolic syndrome, and liver injury. In this review, we have focused on the molecular mechanism underlying inflammatory pathways in insulin resistance and NAFLD triggered by hypoxic conditions, so frequent in obesity. These two elements are modulated by multiple factors like diet, microbiota, or genetic background that can intensify and even perpetuate the inflammatory response. Importantly, inflammation mediated by innate immunity and hypoxia may lead to the development of HCC, among other tumors. From a further and deeper understanding of the molecular basis underlaying HCC pathogenesis new approaches and molecular targets will be developed.

\section{Disclosure}

Javier Crespo is senior author.

\section{Conflict of Interests}

Authors declare no conflict of interests.

\section{Acknowledgments}

The study was supported by Instituto de Salud Carlos III Grant PI12/02026, Health Research and Development Strategy (AES) under the Spanish State Plan for Scientific and Technical Research and Innovation 2012-2015, and Spanish Society of Digestive Diseases (SEPD) Research Grant 2012.

\section{References}

[1] P. Angulo, "Nonalcoholic fatty liver disease," The New England Journal of Medicine, vol. 346, no. 16, pp. 1221-1231, 2002.

[2] S. H. Caldwell and D. M. Crespo, "The spectrum expanded: cryptogenic cirrhosis and the natural history of non-alcoholic fatty liver disease," Journal of Hepatology, vol. 40, no. 4, pp. 578$584,2004$.

[3] R. Loomba and A. J. Sanyal, "The global NAFLD epidemic," Nature Reviews Gastroenterology \& Hepatology, vol. 10, no. 11, pp. 686-690, 2013.

[4] G. Vernon, A. Baranova, and Z. M. Younossi, "Systematic review: the epidemiology and natural history of non-alcoholic fatty liver disease and non-alcoholic steatohepatitis in adults," Alimentary Pharmacology \& Therapeutics, vol. 34, no. 3, pp. 274-285, 2011.

[5] M. Ng, T. Fleming, M. Robinson, and et al, "Global, regional, and national prevalence of overweight and obesity in children and adults during 1980-2013: a systematic analysis for the Global Burden of Disease Study 2013," The Lancet, vol. 384, no. 9945, pp. 766-781, 2014.

[6] B. A. Swinburn, G. Sacks, K. D. Hall et al., "The global obesity pandemic: shaped by global drivers and local environments," The Lancet, vol. 378, no. 9793, pp. 804-814, 2011.

[7] G. Marchesini, S. Moscatiello, S. Di Domizio, and G. Forlani, "Obesity-associated liver disease," The Journal of Clinical Endocrinology and Metabolism, vol. 93, supplement 1, no. 11, pp. S74S80, 2008.
[8] A. T. Murugan and G. Sharma, "Obesity and respiratory diseases," Chronic Respiratory Disease, vol. 5, no. 4, pp. 233-242, 2008.

[9] G. Targher, "Non-alcoholic fatty liver disease, the metabolic syndrome and the risk of cardiovascular disease: the plot thickens," Diabetic Medicine, vol. 24, no. 1, pp. 1-6, 2007.

[10] Z. M. Younossi, M. Stepanova, M. Afendy et al., "Changes in the prevalence of the most common causes of chronic liver diseases in the United States from 1988 to 2008," Clinical Gastroenterology and Hepatology, vol. 9, no. 6, pp. 524.el-530.el, 2011.

[11] J. Aron-Wisnewsky, C. Minville, J. Tordjman et al., "Chronic intermittent hypoxia is a major trigger for non-alcoholic fatty liver disease in morbid obese," Journal of Hepatology, vol. 56, no. 1, pp. 225-233, 2012.

[12] G. Musso, M. Cassader, C. Olivetti, F. Rosina, G. Carbone, and R. Gambino, "Association of obstructive sleep apnoea with the presence and severity of non-alcoholic fatty liver disease. A systematic review and meta-analysis," Obesity Reviews, vol. 14, no. 5, pp. 417-431, 2013.

[13] E. A. Pulixi, E. Tobaldini, P. M. Battezzati et al., "Risk of obstructive sleep apnea with daytime sleepiness is associated with liver damage in non-morbidly obese patients with nonalcoholic fatty liver disease," PLoS ONE, vol. 9, no. 4, Article ID e96349, 2014.

[14] V. Nobili, R. Cutrera, D. Liccardo et al., "Obstructive sleep apnea syndrome affects liver histology and inflammatory cell activation in pediatric nonalcoholic fatty liver disease, regardless of obesity/insulin resistance," American Journal of Respiratory and Critical Care Medicine, vol. 189, no. 1, pp. 66-76, 2014.

[15] T. Young, J. Skatrud, and P. E. Peppard, "Risk factors for obstructive sleep apnea in adults," Journal of the American Medical Association, vol. 291, no. 16, pp. 2013-2016, 2004.

[16] S. Tufik, R. Santos-Silva, J. A. Taddei, and L. R. A. Bittencourt, "Obstructive sleep apnea syndrome in the so paulo epidemiologic sleep study," Sleep Medicine, vol. 11, no. 5, pp. 441-446, 2010.

[17] P. E. Peppard, T. Young, J. H. Barnet, M. Palta, E. W. Hagen, and K. M. Hla, "Increased prevalence of sleep-disordered breathing in adults," American Journal of Epidemiology, vol. 177, no. 9, pp. 1006-1014, 2013.

[18] N. A. Dewan, F. J. Nieto, and V. K. Somers, "Intermittent hypoxemia and OSA: implications for comorbidities," Chest, vol. 147, no. 1, pp. 266-274, 2015.

[19] J. Carabelli, A. L. Burgueño, M. S. Rosselli et al., "High fat dietinduced liver steatosis promotes an increase in liver mitochondrial biogenesis in response to hypoxia," Journal of Cellular and Molecular Medicine, vol. 15, no. 6, pp. 1329-1338, 2011.

[20] M. Hernández-Guerra, Z. A. de Ganzo, Y. González-Méndez et al., "Chronic intermittent hypoxia aggravates intrahepatic endothelial dysfunction in cirrhotic rats," Hepatology, vol. 57, no. 4, pp. 1564-1574, 2013.

[21] Y. Liu, Z. Ma, C. Zhao et al., "HIF-1alpha and HIF-2alpha are critically involved in hypoxia-induced lipid accumulation in hepatocytes through reducing PGC-lalpha-mediated fatty acid beta-oxidation," Toxicology Letters, vol. 226, no. 2, pp. 117-123, 2014.

[22] B. Nath, I. Levin, T. Csak et al., "Hepatocyte-specific hypoxiainducible factor- $1 \alpha$ is a determinant of lipid accumulation and liver injury in alcohol-induced steatosis in mice," Hepatology, vol. 53, no. 5, pp. 1526-1537, 2011. 
[23] A.-C. Piguet, D. Stroka, A. Zimmermann, and J.-F. Dufour, "Hypoxia aggravates non-alcoholic steatohepatitis in mice lacking hepatocellular PTEN," Clinical Science, vol. 118, no. 6, pp. 401-410, 2010.

[24] V. Savransky, S. Bevans, A. Nanayakkara et al., "Chronic intermittent hypoxia causes hepatitis in a mouse model of dietinduced fatty liver," The American Journal of Physiology-Gastrointestinal and Liver Physiology, vol. 293, no. 4, pp. G871-G877, 2007.

[25] V. Savransky, A. Nanayakkara, A. Vivero et al., "Chronic intermittent hypoxia predisposes to liver injury," Hepatology, vol. 45, no. 4, pp. 1007-1013, 2007.

[26] G. L. Semenza, "Oxygen sensing, homeostasis, and disease," The New England Journal of Medicine, vol. 365, no. 6, pp. 537-547, 2011.

[27] A. Palazon, A. W. Goldrath, V. Nizet, and R. S. Johnson, "HIF transcription factors, inflammation, and immunity," Immunity, vol. 41, no. 4, pp. 518-528, 2014.

[28] G. L. Wang, B.-H. Jiang, E. A. Rue, and G. L. Semenza, "Hypoxia-inducible factor 1 is a basic-helix-loop-helix-PAS heterodimer regulated by cellular $\mathrm{O}_{2}$ tension," Proceedings of the National Academy of Sciences of the United States of America, vol. 92, no. 12, pp. 5510-5514, 1995.

[29] G. L. Semenza, "Oxygen sensing, hypoxia-inducible factors, and disease pathophysiology," Annual Review of Pathology: Mechanisms of Disease, vol. 9, pp. 47-71, 2014.

[30] Z. Arany, L. E. Huang, R. Eckner et al., "An essential role for p300/CBP in the cellular response to hypoxia," Proceedings of the National Academy of Sciences of the United States of America, vol. 93, no. 23, pp. 12969-12973, 1996.

[31] H. K. Eltzschig and P. Carmeliet, "Hypoxia and inflammation," The New England Journal of Medicine, vol. 364, no. 7, pp. 656665, 2011.

[32] C. C. Blouin, E. L. Pagé, G. M. Soucy, and D. E. Richard, "Hypoxic gene activation by lipopolysaccharide in macrophages: implication of hypoxia-inducible factor $1 \alpha$," Blood, vol. 103, no. 3, pp. 1124-1130, 2004.

[33] L.-W. Chen, L. Egan, Z.-W. Li, F. R. Greten, M. F. Kagnoff, and M. Karin, "The two faces of IKK and NF-kappaB inhibition: prevention of systemic inflammation but increased local injury following intestinal ischemia-reperfusion," Nature Medicine, vol. 9, no. 5, pp. 575-581, 2003.

[34] J. Kuhlicke, J. S. Frick, J. C. Morote-Garcia, P. Rosenberger, and H. K. Eltzschig, "Hypoxia inducible factor (HIF)-1 coordinates induction of Toll-like receptors TLR2 and TLR6 during hypoxia," PLoS ONE, vol. 2, no. 12, Article ID el364, 2007.

[35] R. Cao, X. Zhao, S. Li et al., "Hypoxia induces dysregulation of lipid metabolism in HepG2 cells via activation of HIF-2 $\alpha$," Cellular Physiology and Biochemistry, vol. 34, no. 5, pp. 14271441, 2014.

[36] S. Parathath, S. L. Mick, J. E. Feig et al., "Hypoxia is present in murine atherosclerotic plaques and has multiple adverse effects on macrophage lipid metabolism," Circulation Research, vol. 109, no. 10, pp. 1141-1152, 2011.

[37] E. Furuta, S. K. Pai, R. Zhan et al., "Fatty acid synthase gene is up-regulated by hypoxia via activation of Akt and sterol regulatory element binding protein-1," Cancer Research, vol. 68, no. 4, pp. 1003-1011, 2008.

[38] E. B. Rankin, J. Rha, M. A. Selak et al., "Hypoxia-inducible factor 2 regulates hepatic lipid metabolism," Molecular and Cellular Biology, vol. 29, no. 16, pp. 4527-4538, 2009.
[39] A. Qu, M. Taylor, X. Xue et al., "Hypoxia-inducible transcription factor $2 \alpha$ promotes steatohepatitis through augmenting lipid accumulation, inflammation, and fibrosis," Hepatology, vol. 54, no. 2, pp. 472-483, 2011.

[40] Z. Yun, H. L. Maecker, R. S. Johnson, and A. J. Giaccia, "Inhibition of PPAR gamma 2 gene expression by the HIF-1-regulated gene DEC1/Stra13: a mechanism for regulation of adipogenesis by hypoxia," Developmental Cell, vol. 2, no. 3, pp. 331-341, 2002.

[41] Y. Nishiyama, N. Goda, M. Kanai et al., "HIF-1 $\alpha$ induction suppresses excessive lipid accumulation in alcoholic fatty liver in mice," Journal of Hepatology, vol. 56, no. 2, pp. 441-447, 2012.

[42] C. Reinke, S. Bevans-Fonti, L. F. Drager, M.-K. Shin, and V. Y. Polotsky, "Effects of different acute hypoxic regimens on tissue oxygen profiles and metabolic outcomes," Journal of Applied Physiology, vol. 111, no. 3, pp. 881-890, 2011.

[43] W. Trzepizur, A. Gaceb, C. Arnaud et al., "Vascular and hepatic impact of short-term intermittent hypoxia in a mouse model of metabolic syndrome," PloS ONE, vol. 10, no. 5, Article ID e0124637, 2015.

[44] C. M. Taniguchi, E. C. Finger, A. J. Krieg et al., "Cross-talk between hypoxia and insulin signaling through $\mathrm{Phd} 3$ regulates hepatic glucose and lipid metabolism and ameliorates diabetes," Nature Medicine, vol. 19, no. 10, pp. 1325-1330, 2013.

[45] K. Wei, S. M. Piecewicz, L. M. McGinnis et al., "A liver Hif$2 \alpha$-Irs2 pathway sensitizes hepatic insulin signaling and is modulated by Vegf inhibition," Nature Medicine, vol. 19, no. 10, pp. 1331-1337, 2013.

[46] D. Luo, Z. Wang, J. Wu, C. Jiang, and J. Wu, "The role of hypoxia inducible factor-1 in hepatocellular carcinoma," BioMed Research International, vol. 2014, Article ID 409272, 11 pages, 2014.

[47] C. C.-L. Wong, A. K.-L. Kai, and I. O.-L. Ng, “The impact of hypoxia in hepatocellular carcinoma metastasis," Frontiers of Medicine in China, vol. 8, no. 1, pp. 33-41, 2014.

[48] Y. Yang, M. Sun, L. Wang, and B. Jiao, "HIFs, angiogenesis, and cancer," Journal of Cellular Biochemistry, vol. 114, no. 5, pp. 967974, 2013.

[49] G. S. Hotamisligil and B. M. Spiegelman, "Tumor necrosis factor alpha: a key component of the obesity-diabetes link," Diabetes, vol. 43, no. 11, pp. 1271-1278, 1994.

[50] C. N. Lumeng, I. Maillard, and A. R. Saltiel, "T-ing up inflammation in fat," Nature Medicine, vol. 15, no. 8, pp. 846-847, 2009.

[51] G. Matarese, C. Procaccini, V. De Rosa, T. L. Horvath, and A. La Cava, "Regulatory T cells in obesity: the leptin connection," Trends in Molecular Medicine, vol. 16, no. 6, pp. 247-256, 2010.

[52] Q. Lin and Z. Yun, "The hypoxia-inducible factor pathway in adipocytes: the role of HIF-2 in adipose inflammation and hypertrophic cardiomyopathy," Frontiers in Endocrinology, vol. 6, article 39, 2015.

[53] Y. S. Lee, J.-W. Kim, O. Osborne et al., "Increased adipocyte $\mathrm{O}_{2}$ consumption triggers HIF-lalpha, causing inflammation and insulin resistance in obesity," Cell, vol. 157, no. 6, pp. 1339-1352, 2014.

[54] P. Trayhurn, "Hypoxia and adipocyte physiology: implications for adipose tissue dysfunction in obesity," Annual Review of Nutrition, vol. 34, pp. 207-236, 2014.

[55] J. Ye, "Adipose tissue vascularization: its role in chronic inflammation," Current Diabetes Reports, vol. 11, no. 3, pp. 203-210, 2011.

[56] G. H. Goossens, A. Bizzarri, N. Venteclef et al., "Increased adipose tissue oxygen tension in obese compared with lean men 
is accompanied by insulin resistance, impaired adipose tissue capillarization, and inflammation," Circulation, vol. 124, no. 1 , pp. 67-76, 2011.

[57] J. Ye, Z. Gao, J. Yin, and Q. He, "Hypoxia is a potential risk factor for chronic inflammation and adiponectin reduction in adipose tissue of ob/ob and dietary obese mice," The American Journal of Physiology-Endocrinology and Metabolism, vol. 293, no. 4, pp. E1118-E1128, 2007.

[58] L. Hodson, "Adipose tissue oxygenation: effects on metabolic function," Adipocyte, vol. 3, no. 1, pp. 75-80, 2014.

[59] L. Hodson, S. M. Humphreys, F. Karpe, and K. N. Frayn, "Metabolic signatures of human adipose tissue hypoxia in obesity," Diabetes, vol. 62, no. 5, pp. 1417-1425, 2013.

[60] Y. Kihira, M. Miyake, M. Hirata et al., "Deletion of hypoxiainducible factor-lalpha in adipocytes enhances glucagon-like peptide-1 secretion and reduces adipose tissue inflammation," PLoS ONE, vol. 9, no. 4, Article ID e93856, 2014.

[61] G. Targher, C. P. Day, and E. Bonora, "Risk of cardiovascular disease in patients with nonalcoholic fatty liver disease," The New England Journal of Medicine, vol. 363, no. 14, pp. 1341-1350, 2010.

[62] S. E. Shoelson, L. Herrero, and A. Naaz, "Obesity, inflammation, and insulin resistance," Gastroenterology, vol. 132, no. 6, pp. 2169-2180, 2007.

[63] H. Tilg and A. R. Moschen, "Insulin resistance, inflammation, and non-alcoholic fatty liver disease," Trends in Endocrinology and Metabolism, vol. 19, no. 10, pp. 371-379, 2008.

[64] S. Kiechl, E. Lorenz, M. Reindl et al., "Toll-like receptor 4 polymorphisms and atherogenesis," The New England Journal of Medicine, vol. 347, no. 3, pp. 185-192, 2002.

[65] Y. S. Roh and E. Seki, "Toll-like receptors in alcoholic liver disease, non-alcoholic steatohepatitis and carcinogenesis," Journal of Gastroenterology and Hepatology, vol. 28, no. 1, pp. 38-42, 2013.

[66] N. Stefan, K. Kantartzis, and H.-U. Häring, "Causes and metabolic consequences of fatty liver," Endocrine Reviews, vol. 29, no. 7, pp. 939-960, 2008.

[67] T. Kawai and S. Akira, "The role of pattern-recognition receptors in innate immunity: update on toll-like receptors," Nature Immunology, vol. 11, no. 5, pp. 373-384, 2010.

[68] S. Akira, K. Takeda, and T. Kaisho, "Toll-like receptors: critical proteins linking innate and acquired immunity," Nature Immunology, vol. 2, no. 8, pp. 675-680, 2001.

[69] D. Ye, F. Y. L. Li, K. S. L. Lam et al., “Toll-like receptor-4 mediates obesity-induced non-alcoholic steatohepatitis through activation of X-box binding protein-1 in mice," Gut, vol. 61, no. 7, pp. 1058-1067, 2012.

[70] T. Csak, A. Velayudham, I. Hritz et al., "Deficiency in myeloid differentiation factor-2 and toll-like receptor 4 expression attenuates nonalcoholic steatohepatitis and fibrosis in mice," American Journal of Physiology-Gastrointestinal and Liver Physiology, vol. 300, no. 3, pp. 433-441, 2011.

[71] S. Inokuchi, H. Tsukamoto, E. Park, Z.-X. Liu, D. A. Brenner, and E. Seki, "Toll-like receptor 4 mediates alcohol-induced steatohepatitis through bone marrow-derived and endogenous liver cells in mice," Alcoholism: Clinical and Experimental Research, vol. 35, no. 8, pp. 1509-1518, 2011.

[72] C. A. Rivera, L. Gaskin, M. Allman et al., “Toll-like receptor-2 deficiency enhances non-alcoholic steatohepatitis," BMC Gastroenterology, vol. 10, article 52, 2010.
[73] G. Szabo, A. Velayudham, L. Romics Jr., and P. Mandrekar, "Modulation of non-alcoholic steatohepatitis by pattern recognition receptors in mice: the role of toll-like receptors 2 and 4," Alcoholism: Clinical and Experimental Research, vol. 29, no. 11, supplement, pp. 140S-145S, 2005.

[74] M. Vijay-Kumar, J. D. Aitken, F. A. Carvalho et al., "Metabolie syndrome and altered gut microbiota in mice lacking toll-like receptor 5," Science, vol. 328, no. 5975, pp. 228-231, 2010.

[75] S. Akira, S. Uematsu, and O. Takeuchi, "Pathogen recognition and innate immunity," Cell, vol. 124, no. 4, pp. 783-801, 2006.

[76] Y.-C. Lu, W.-C. Yeh, and P. S. Ohashi, "LPS/TLR4 signal transduction pathway," Cytokine, vol. 42, no. 2, pp. 145-151, 2008.

[77] S. J. Creely, P. G. McTernan, C. M. Kusminski et al., "Lipopolysaccharide activates an innate immune system response in human adipose tissue in obesity and type 2 diabetes," American Journal of Physiology_Endocrinology and Metabolism, vol. 292, no. 3, pp. E740-E747, 2007.

[78] P. J. Pussinen, A. S. Havulinna, M. Lehto, J. Sundvall, and V. Salomaa, "Endotoxemia is associated with an increased risk of incident diabetes," Diabetes Care, vol. 34, no. 2, pp. 392-397, 2011.

[79] A. G. Ruiz, F. Casafont, J. Crespo et al., "Lipopolysaccharidebinding protein plasma levels and liver TNF-alpha gene expression in obese patients: evidence for the potential role of endotoxin in the pathogenesis of non-alcoholic steatohepatitis," Obesity Surgery, vol. 17, no. 10, pp. 1374-1380, 2007.

[80] A. Douhara, K. Moriya, H. Yoshiji et al., "Reduction of endotoxin attenuates liver fibrosis through suppression of hepatic stellate cell activation and remission of intestinal permeability in a rat non-alcoholic steatohepatitis model," Molecular Medicine Reports, vol. 11, no. 3, pp. 1693-1700, 2015.

[81] R. Singh, J. Bullard, M. Kalra et al., "Status of bacterial colonization, Toll-like receptor expression and nuclear factor-kappa B activation in normal and diseased human livers," Clinical Immunology, vol. 138, no. 1, pp. 41-49, 2011.

[82] P. D. Cani, J. Amar, M. A. Iglesias et al., "Metabolic endotoxemia initiates obesity and insulin resistance," Diabetes, vol. 56, no. 7, pp. 1761-1772, 2007.

[83] O. E. Frasinariu, S. Ceccarelli, A. Alisi, E. Moraru, and V. Nobili, "Gut-liver axis and fibrosis in nonalcoholic fatty liver disease: an input for novel therapies," Digestive and Liver Disease, vol. 45, no. 7, pp. 543-551, 2013.

[84] S. Pendyala, J. M. Walker, and P. R. Holt, "A high-fat diet is associated with endotoxemia that originates from the gut," Gastroenterology, vol. 142, no. 5, pp. 1100-1101.e2, 2012.

[85] R. N. Dickerson and C. B. Karwoski, "Endotoxin-mediated hepatic lipid accumulation during parenteral nutrition in rats," Journal of the American College of Nutrition, vol. 21, no. 4, pp. 351-356, 2002.

[86] E. J. Drenick, J. Fisler, and D. Johnson, “Hepatic steatosis after intestinal bypass-prevention and reversal by metronidazole, irrespective of protein-calorie malnutrition," Gastroenterology, vol. 82, no. 3, pp. 535-548, 1982.

[87] K. C. El Kasmi, A. L. Anderson, M. W. Devereaux et al., “Tolllike receptor 4-dependent Kupffer cell activation and liver injury in a novel mouse model of parenteral nutrition and intestinal injury," Hepatology, vol. 55, no. 5, pp. 1518-1528, 2012.

[88] M. Poggi, D. Bastelica, P. Gual et al., "C $3 \mathrm{H} / \mathrm{HeJ}$ mice carrying a toll-like receptor 4 mutation are protected against the development of insulin resistance in white adipose tissue in response to a high-fat diet," Diabetologia, vol. 50, no. 6, pp. 1267-1276, 2007. 
[89] M. R. Dasu and I. Jialal, "Free fatty acids in the presence of high glucose amplify monocyte inflammation via Toll-like receptors," American Journal of Physiology-Endocrinology and Metabolism, vol. 300, no. 1, pp. E145-E154, 2011.

[90] J. Y. Lee, J. Ye, Z. Gao et al., "Reciprocal modulation of toll-like receptor-4 signaling pathways involving MyD88 and phosphatidylinositol 3-kinase/AKT by saturated and polyunsaturated fatty acids," The Journal of Biological Chemistry, vol. 278, no. 39, pp. 37041-37051, 2003.

[91] J. Y. Lee, K. H. Sohn, S. H. Rhee, and D. Hwang, "Saturated fatty acids, but not unsaturated fatty acids, induce the expression of cyclooxygenase-2 mediated through Toll-like receptor 4," The Journal of Biological Chemistry, vol. 276, no. 20, pp. 1668316689, 2001.

[92] H. Shi, M. V. Kokoeva, K. Inouye, I. Tzameli, H. Yin, and J. S. Flier, "TLR4 links innate immunity and fatty acid-induced insulin resistance," The Journal of Clinical Investigation, vol. 116, no. 11, pp. 3015-3025, 2006.

[93] D. H. Dapito, A. Mencin, G.-Y. Gwak et al., "Promotion of hepatocellular carcinoma by the intestinal microbiota and TLR4," Cancer Cell, vol. 21, no. 4, pp. 504-516, 2012.

[94] M. Darnaud, J. Faivre, and N. Moniaux, "Targeting gut flora to prevent progression of hepatocellular carcinoma," Journal of Hepatology, vol. 58, no. 2, pp. 385-387, 2013.

[95] S. Maeda, H. Kamata, J.-L. Luo, H. Leffert, and M. Karin, "IKK $\beta$ couples hepatocyte death to cytokine-driven compensatory proliferation that promotes chemical hepatocarcinogenesis," Cell, vol. 121, no. 7, pp. 977-990, 2005.

[96] T. Sakurai, G. He, A. Matsuzawa et al., "Hepatocyte necrosis induced by oxidative stress and IL- $1 \alpha$ release mediate carcinogen-induced compensatory proliferation and liver tumorigenesis," Cancer Cell, vol. 14, no. 2, pp. 156-165, 2008.

[97] T. Sakurai, S. Maeda, L. Chang, and M. Karin, "Loss of hepatic NF- $\kappa \mathrm{B}$ activity enhances chemical hepatocarcinogenesis through sustained c-Jun N-terminal kinase 1 activation," Proceedings of the National Academy of Sciences of the United States of America, vol. 103, no. 28, pp. 10544-10551, 2006.

[98] L.-X. Yu, H.-X. Yan, Q. Liu et al., "Endotoxin accumulation prevents carcinogen-induced apoptosis and promotes liver tumorigenesis in rodents," Hepatology, vol. 52, no. 4, pp. 1322-1333, 2010.

[99] R. Taira, S. Yamaguchi, K. Shimizu, K. Nakamura, T. Ayabe, and T. Taira, "Bacterial cell wall components regulate adipokine secretion from visceral adipocytes," Journal of Clinical Biochemistry and Nutrition, vol. 56, no. 2, pp. 149-154, 2015.

[100] M. Raman, I. Ahmed, P. M. Gillevet et al., "Fecal microbiome and volatile organic compound metabolome in obese humans with nonalcoholic fatty liver disease," Clinical Gastroenterology and Hepatology, vol. 11, no. 7, pp. 868.e3-875.e3, 2013.

[101] K. Miura, L. Yang, N. van Rooijen, D. A. Brenner, H. Ohnishi, and E. Seki, "Toll-like receptor 2 and palmitic acid cooperatively contribute to the development of nonalcoholic steatohepatitis through inflammasome activation in mice," Hepatology, vol. 57, no. 2, pp. 577-589, 2013.

[102] J. A. Ehses, D. T. Meier, S. Wueest et al., "Toll-like receptor 2deficient mice are protected from insulin resistance and beta cell dysfunction induced by a high-fat diet," Diabetologia, vol. 53, no. 8, pp. 1795-1806, 2010.

[103] N. M. Al-Daghri, M. Clerici, O. Al-Attas et al., "A nonsense polymorphism (R392X) in TLR5 protects from obesity but predisposes to diabetes," Journal of Immunology, vol. 190, no. 7, pp. 3716-3720, 2013.
[104] M. K. Mohammad, M. Morran, B. Slotterbeck et al., "Dysregulated Toll-like receptor expression and signaling in bone marrow-derived macrophages at the onset of diabetes in the non-obese diabetic mouse," International Immunology, vol. 18, no. 7, pp. 1101-1113, 2006.

[105] K. Miura, Y. Kodama, S. Inokuchi et al., “Toll-like receptor 9 promotes steatohepatitis by induction of interleukin-lbeta in mice," Gastroenterology, vol. 139, no. 1, pp. 323-334.e7, 2010.

[106] E. Gäbele, K. Dostert, C. Hofmann et al., "DSS induced colitis increases portal LPS levels and enhances hepatic inflammation and fibrogenesis in experimental NASH," Journal of Hepatology, vol. 55, no. 6, pp. 1391-1399, 2011.

[107] G. C. Farrell and C. Z. Larter, "Nonalcoholic fatty liver disease: from steatosis to cirrhosis," Hepatology, vol. 43, no. 2, supplement 1, pp. S99-S112, 2006.

[108] C. P. Day and O. F. W. James, "Steatohepatitis: a tale of two 'Hits'?” Gastroenterology, vol. 114, no. 4, pp. 842-845, 1998.

[109] H. Tilg and A. R. Moschen, "Evolution of inflammation in nonalcoholic fatty liver disease: the multiple parallel hits hypothesis," Hepatology, vol. 52, no. 5, pp. 1836-1846, 2010.

[110] J. Rius, M. Guma, C. Schachtrup et al., "NF- $\kappa$ B links innate immunity to the hypoxic response through transcriptional regulation of HIF-1 $\alpha$," Nature, vol. 453, no. 7196, pp. 807-811, 2008.

[111] S. Y. Kim, Y. J. Choi, S. M. Joung, B. H. Lee, Y.-S. Jung, and J. Y. Lee, "Hypoxic stress up-regulates the expression of Toll-like receptor 4 in macrophages via hypoxia-inducible factor," Immunology, vol. 129, no. 4, pp. 516-524, 2010.

[112] J. Crespo, A. Cayoen, P. Fernendez-Gil et al., "Gene expression of tumor necrosis factor $\alpha$ and TNF-receptors, p55 and p75, in nonalcoholic steatohepatitis patients," Hepatology, vol. 34, no. 6, pp. 1158-1163, 2001.

[113] E. Maury and S. M. Brichard, "Adipokine dysregulation, adipose tissue inflammation and metabolic syndrome," Molecular and Cellular Endocrinology, vol. 314, no. 1, pp. 1-16, 2010. 


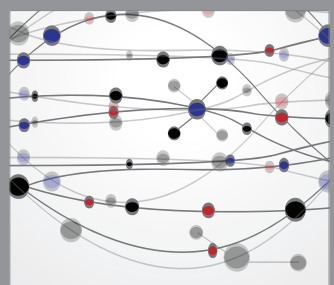

The Scientific World Journal
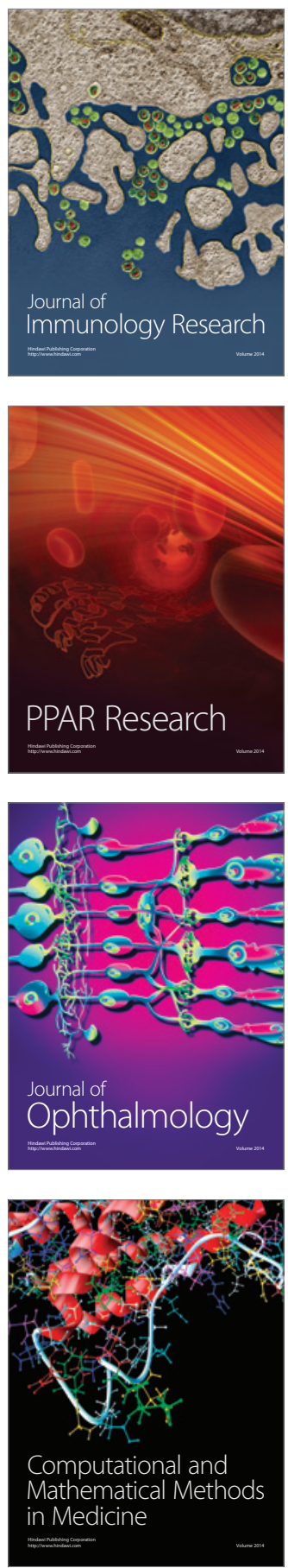

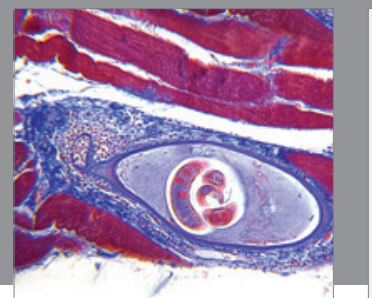

Gastroenterology

Research and Practice
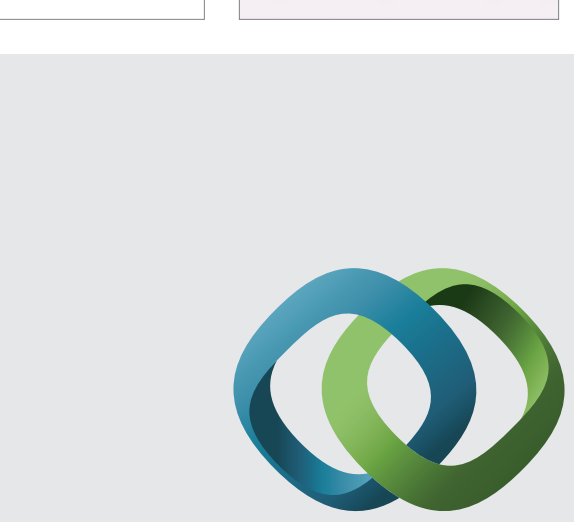

\section{Hindawi}

Submit your manuscripts at

http://www.hindawi.com
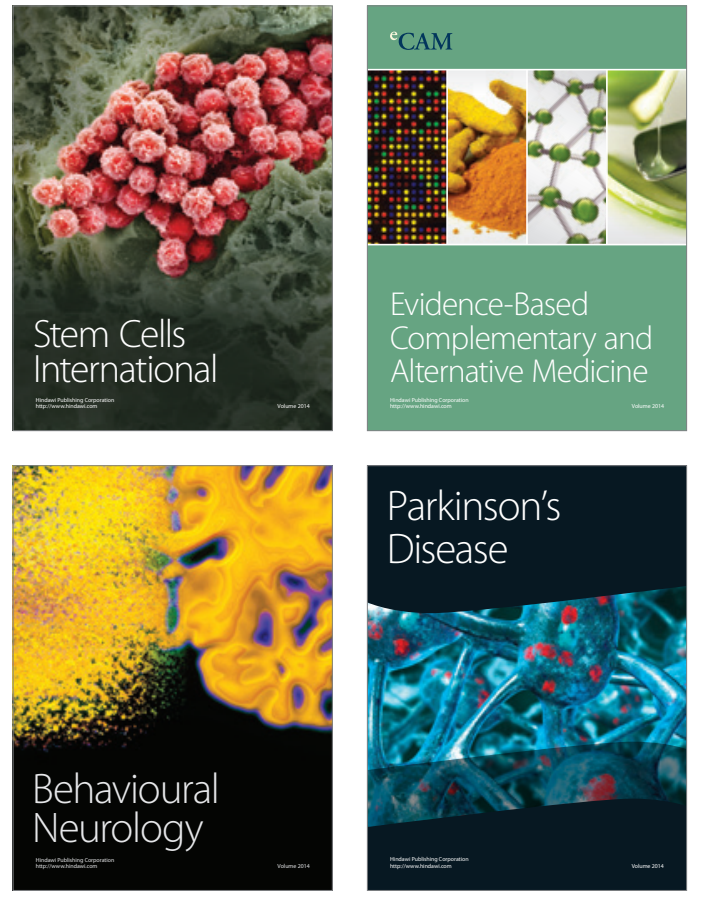
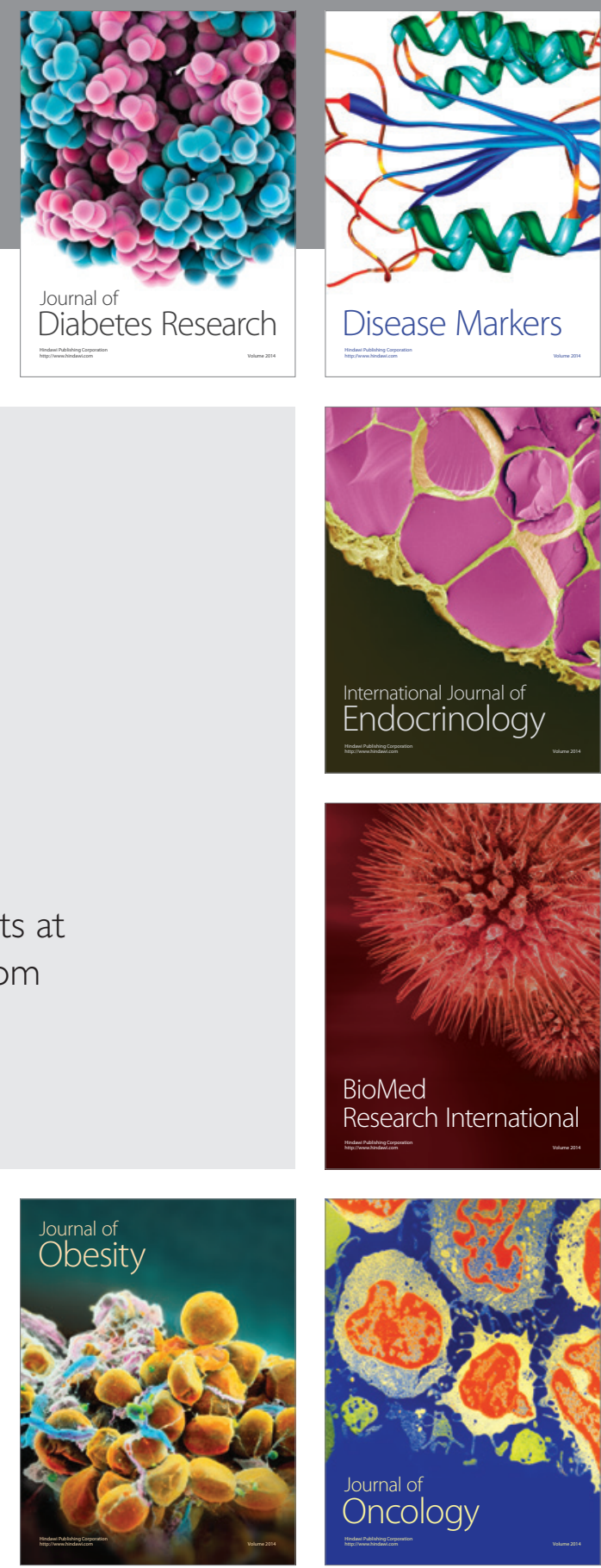

Disease Markers
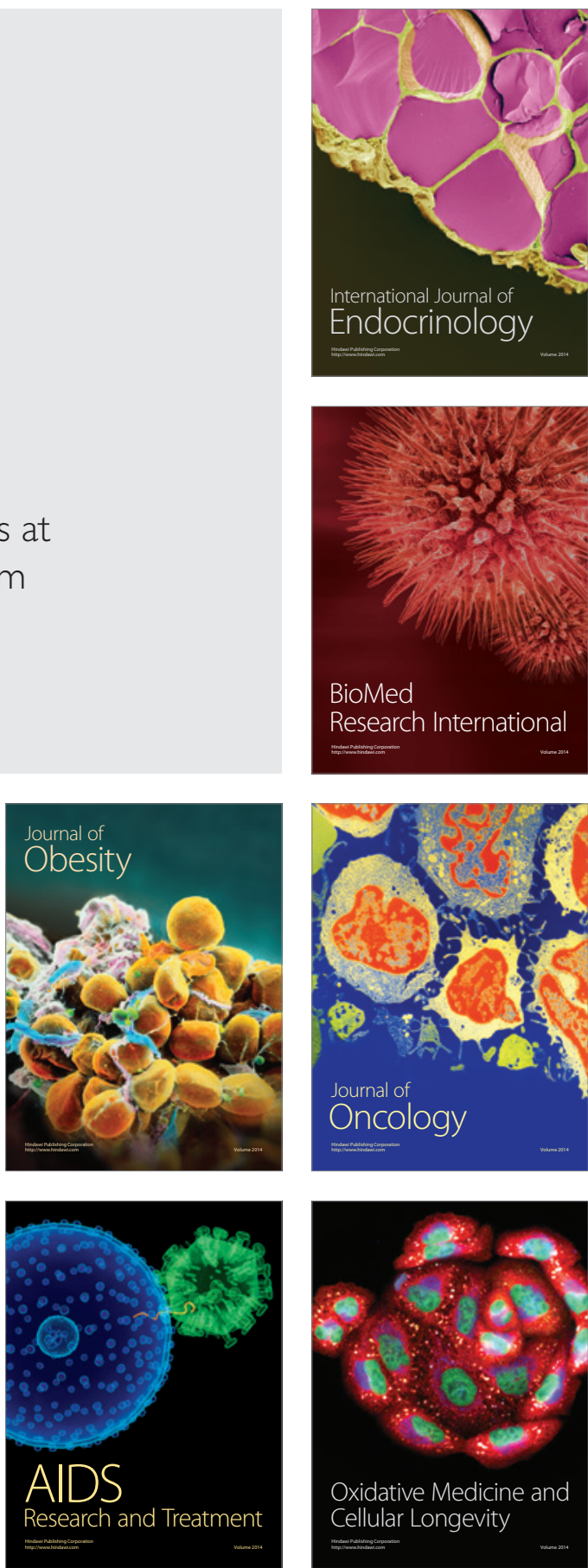